\title{
Comparison of 11 respiratory pathogens among hospitalized children before and during the COVID-19 epidemic in Shenzhen, China
}

\author{
$\mathrm{Li} \mathrm{Li}^{1+}$, Heping Wang ${ }^{1 \dagger}$, Ailiang Liu', Rongjun Wang ${ }^{1}$, Tingting Zhi², Yuejie Zheng ${ }^{1}$, Yanming Bao', \\ Yunsheng Chen ${ }^{1 *}$ and Wenjian Wang ${ }^{1 *}$
}

\begin{abstract}
Background: The effect of SARS-CoV-2 on existing respiratory pathogens in circulation remains uncertain. This study aimed to assess the impact of SARS-CoV-2 on the prevalence of respiratory pathogens among hospitalized children.

Methods: This study enrolled hospitalized children with acute respiratory infections in Shenzhen Children's Hospital from September to December 2019 (before the COVID-19 epidemic) and those from September to December 2020 (during the COVID-19 epidemic). Nasopharyngeal swabs were collected, and respiratory pathogens were detected using multiplex PCR. The absolute case number and detection rates of 11 pathogens were collected and analyzed.

Results: A total of 5696 children with respiratory tract infection received multiplex PCR examination for respiratory pathogens: 2298 from September to December 2019 and 3398 from September to December 2020. At least one pathogen was detected in 1850 (80.5\%) patients in 2019, and in 2380 (70.0\%) patients in 2020; the detection rate in 2020 was significantly lower than that in 2019.The Influenza A (InfA) detection rate was 5.6\% in 2019, but 0\% in 2020. The detection rates of Mycoplasma pneumoniae, Human adenovirus, and Human rhinovirus also decreased from 20\% (460), 8.9\% (206), and 41.8\% (961) in 2019 to 1.0\% (37), 2.1\% (77), and 25.6\% (873) in 2020, respectively. In contrast, the detection rates of Human respiratory syncytial virus, Human parainfluenza virus, and Human metapneumovirus increased from $6.6 \%$ (153), 9.9\% (229), and $0.5 \%$ (12) in 2019 to $25.6 \%$ (873), 15.5\% (530), and $7.2 \%$ (247) in 2020, respectively $(p<0.0001)$.

Conclusions: Successful containment of seasonal influenza as a result of COVID-19 control measures will ensure we are better equipped to deal with future outbreaks of both influenza and COVID-19.Caused by virus competition, the detection rates of Human respiratory syncytial virus, Human parainfluenza virus, and Human metapneumovirus increased in Shenzhen,that reminds us we need to take further monitoring and preventive measures in the next epidemic season.
\end{abstract}

Keywords: SARS-CoV-2, Respiratory pathogens, Prevalence, Children

*Correspondence: chenyunsheng66@163.com; wwjxx@126.com

${ }^{\dagger} \mathrm{Li}$ Li and Heping Wang have contributed equally to this work

1 Department of Respiratory Diseases, Shenzhen Children's Hospital, No. 7019 Yitian Road, Futian District, Shenzhen 518038, Guangdong, China

Full list of author information is available at the end of the article

\section{Background}

Coronavirus disease 2019 (COVID-19), which is caused by severe acute respiratory syndrome coronavirus 2 (SARS-CoV-2), has caused a substantial health burden worldwide. A massive roll out of population-level nonpharmaceutical interventions have been conducted to curb transmission, including stay-at-home orders,

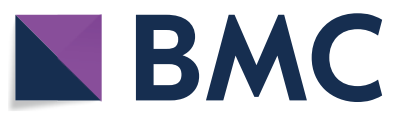

(c) The Author(s) 2021. Open Access This article is licensed under a Creative Commons Attribution 4.0 International License, which permits use, sharing, adaptation, distribution and reproduction in any medium or format, as long as you give appropriate credit to the original author(s) and the source, provide a link to the Creative Commons licence, and indicate if changes were made. The images or other third party material in this article are included in the article's Creative Commons licence, unless indicated otherwise in a credit line to the material. If material is not included in the article's Creative Commons licence and your intended use is not permitted by statutory regulation or exceeds the permitted use, you will need to obtain permission directly from the copyright holder. To view a copy of this licence, visit http://creativecommons.org/licenses/by/4.0/. The Creative Commons Public Domain Dedication waiver (http://creativecommons.org/publicdomain/zero/1.0/) applies to the data made available in this article, unless otherwise stated in a credit line to the data. 
the closure of schools and retail spaces, mandated face masks in public, and encouragement of social distancing and hand hygiene. Studies from France, Japan, Singapore, Mexico, and Zhejiang province of China have shown that these measures also coincided with a decline in the number of cases of influenza over the same time period, as compared with previous seasons [1-5]. However, few studies of how seasonal other respiratory pathogens changed during the epidemic. To assess changes in seasonal respiratory viruses during the outbreak of COVID-19 in Shenzhen, hospitalized children with respiratory infections were recruited in Shenzhen Children's Hospital. We compared the absolute case number and detection rates of 11 pathogens in the period from September to December 2019 with those from September to December 2020. Shenzhen is a large migratory city located in southern China. Since the outbreak of the epidemic, Shenzhen has been in the normalization of epidemic prevention and control, From September to December 2020, all the schools and kindergartens were opened, but the wearing of masks, social distancing, and avoidance of gathering-related activities continued to be required. On the way to and from school, students had to wear masks, there was no need to wear masks in school. Children under 2 years of age did not need to wear masks. There were strict boarder controls during this time in Shenzhen. Anyone entering via the Shenzhen port were transferred directly from the port to designated hotels for isolation for at least 14 days and may be transferred to designated hospitals for further treatment if SARS-CoV-19 PCR was tested positive during this time. During the study period, the number of confirmed COVID-19 cases in Shenzhen raised from 465 cases on 1st August 2020 to 482 cases on 31st December 2020 (17 new cases) and all were imported cases.

\section{Methods \\ Patients}

Patients with acute respiratory infections (ARIs) between September to December 2019 and September to December 2020 admitted to the pediatric wards were enrolled in Shenzhen Children's Hospital. The inclusion criteria were as follows: age below 14 years and one or more respiratory symptoms (cough, sore throat, body temperature above $37.5^{\circ} \mathrm{C}$, and dyspnea/tachypnoea). The study protocol was approved by the Ethical Committee of Shenzhen Children's Hospital (number: 201601304). Written informed consent was obtained from the participants' guardians. Clinical and demographic data, as well as samples for testing pathogens, were collected by trained nurses in line with a standardized protocol.

\section{Specimens and detection of pathogens}

Nasopharyngeal swabs were obtained by trained personnel following standard operating procedures within $24 \mathrm{~h}$ after admission. The specimens were transported immediately to the laboratory in sterile viral transport media. The total nucleic acids of each specimen were extracted using EasyPure Viral DNA/RNA Kit (TransGen Biotech, Beijing, China) in accordance with the manufacturer's instructions. Eleven common respiratory pathogens, including Influenza A (InfA), Influenza B (InfB), Human parainfluenza virus (HPIV), Human respiratory syncytial virus (RSV), adenoviruses (AdV), Human metapneumovirus (HMPV), Human rhinovirus (HRV), Human bocavirus $(\mathrm{HBoV})$, Human coronavirus ( $\mathrm{HCoV})$, Chlamydia (Ch), and Mycoplasma pneumoniae (MP), were detected using a GeXP-based multiplex reverse transcription polymerase chain reaction (PCR) assay (Ningbo).

\section{Statistical analysis}

Statistical analyses were conducted using SPSS 23 (SPSS Inc. Chicago, IL, USA). For comparison of categorical data, chi-square or Fisher's exact test was used. $P<0.05$ was considered statistically significant.

\section{Results}

\section{Patient characteristics}

A total of 5696 children with respiratory tract infection were enrolled in this study, 2298 in the period from September to December 2019 and 3398 in the period from September to December 2020. The age ranged from 1 month to 14 years, and the median age was 27.5 months in 2019 and 24 months in 2020. We divided the patients according to age into four groups, as follows: (1) infant group (1 month-1 year old), 713 cases in 2019 and 1071 cases in 2020; (2) toddler group (1-3 years old), 641 cases in 2019 and 1036 cases in 2020; (3) pre-school group (3-6 years old), 647 cases in 2019 and 932 cases in 2020; (4) school children group (6-14 years old), 297 cases in 2019 and 359 cases in 2020. The subjects included 1389 boys $(60.5 \%)$ and 909 girls (39.5\%) (sex ratio, 1.53:1) in 2019, and 2023 boys (59.5\%) and 1375 girls (40.5\%) (sex ratio, 1.48:1) in 2020 . There was no significant difference in sex ratio between 2019 and $2020\left(X^{2}=0.4714\right.$, $P=0.4913)$.

\section{Overall detection percentage of the 11 pathogens}

In 2019, of 2298 specimens, 1850 (80.5\%) tested positive for at least one of the 11 pathogens; in 1295 $(70.0 \%)$ of these positive patients, single pathogen was detected, whereas in 555 (30.0\%) patients, more than two pathogens were detected. In 2020, of 3398 specimens, $2380(70.0 \%)$ tested positive for at least one of the 
Table 1 Comparison of positive rates of 11 respiratory pathogens in 2019 and 2020, the detection rate of InfA was 5.6\% in 2019, but none in 2020

\begin{tabular}{|c|c|c|c|c|}
\hline Pathogens & $\begin{array}{l}2019 \\
N=2298\end{array}$ & $\begin{array}{l}2020 \\
N=3398\end{array}$ & $x^{2}$ & $P$ \\
\hline Human rhinovirus (HRV) & $961(41.8 \%)$ & $873(25.6 \%)$ & 163.3277 & 0.000 \\
\hline Mycoplasma pneumoniae (MP) & $460(20 \%)$ & $37(1.0 \%)$ & 616.7384 & 0.000 \\
\hline Human parainfluenza virus (HPIV) & $229(9.9 \%)$ & $530(15.5 \%)$ & 37.6529 & 0.000 \\
\hline Human adenovirus (AdV) & $206(8.9 \%)$ & $77(2.2 \%)$ & 130.2703 & 0.000 \\
\hline Human respiratory syncytial virus (RSV) & $152(6.6 \%)$ & $683(20.1 \%)$ & 199.2841 & 0.000 \\
\hline Influenza A virus (InfA) & $130(5.6 \%)$ & 0 & 196.7177 & 0.000 \\
\hline Human bocavirus (HBoV) & $87(3.7 \%)$ & $152(4.4 \%)$ & 1.6111 & 0.2040 \\
\hline Human coronavirus (HCoV) & $66(2.8 \%)$ & $123(3.6 \%)$ & 2.3891 & 0.1222 \\
\hline Chlamydia (Ch) & $29(1.2 \%)$ & $22(0.6 \%)$ & 5.8343 & 0.0157 \\
\hline Human metapneumovirus (HMPV) & $12(0.5 \%)$ & $247(7.2 \%)$ & 143.7734 & 0.000 \\
\hline Influenza B virus (InfB) & $3(0.1 \%)$ & $1(<0.1 \%)$ & 0.8164 & 0.3662 \\
\hline
\end{tabular}

In contrast, the detection rates of RSV, HPIV, and HMPV in 2020 increased compared with those in 2019, other pathogens, such as HBoV, InfB, and HCoV, showed similar detection rates between 2019 and 2020

11 pathogens; in $2034(85.5 \%)$ of these positive specimens, single pathogen was detected, and in $346(14.5 \%)$ of patients, there were more than two pathogens. The detection rate in 2020 was significantly lower than that in $2019\left(X^{2}=78.5290, P=0.000\right)$.

\section{Changes of specific pathogens between 2019 and 2020}

The top three pathogens were HRV, MP, and HPIV in 2019, whereas HRV, RSV, and HPIV were dominant in 2020. Five pathogens (InfA, HRV, MP, AdV, and Ch) had a lower detection rate in 2020 than in 2019. The detection rate of InfA was $5.6 \%$ in 2019 , but none in 2020 . In contrast, the detection rates of RSV, HPIV, and HMPV in 2020 increased compared with those in 2019, where the detection rate of RSV showed the most significant increase, from 6.6 to $20.1 \%$. Other pathogens, such as $\mathrm{HBoV}$, InfB, and $\mathrm{HCoV}$, showed similar detection rates between 2019 and 2020 (Table 1).

\section{Changes in specific pathogens based on month and age}

The detection rate of pathogens in school children in 2020 was lower than that in 2019, but no significant differences between the two years were found in other age groups (Fig. 1). There was no difference in monthly trend of the detection rate between 2019 and 2020; in both years, the detection rate decreased from September to December (Fig. 2).

We also found some epidemic patterns of the viral infections from September to December, especially in 2020 after the epidemic. RSV was the most prevalent pathogen between September and October, and its occurrence sharply declined in November. In contrast,
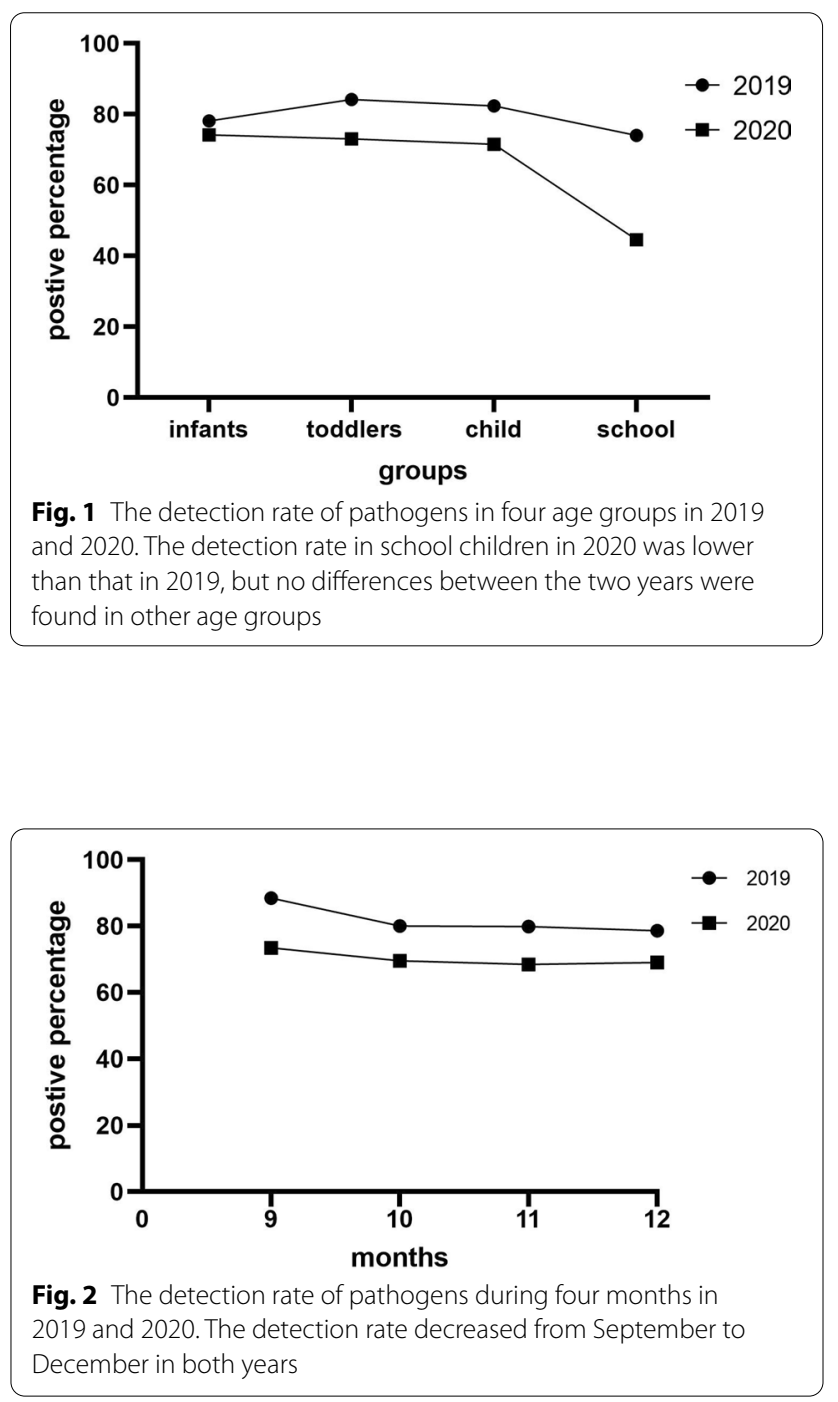


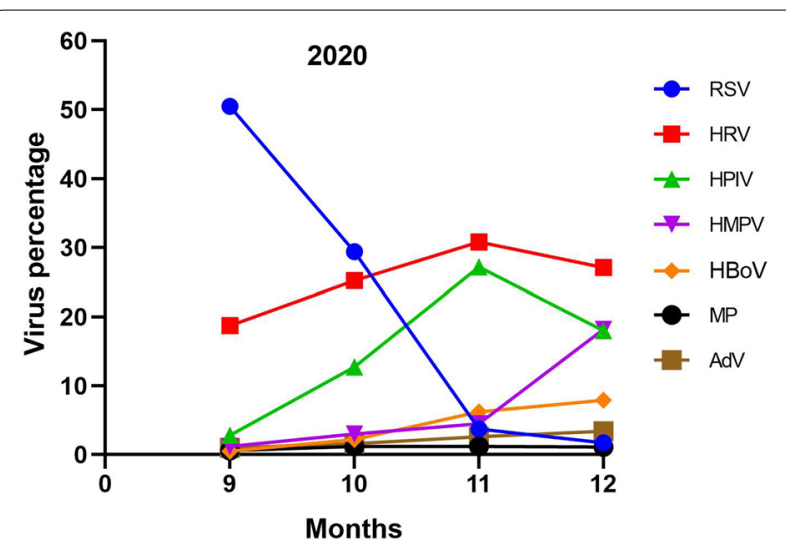

Fig. 3 The detection rate of RSV, HRV, HPIV, HMPV, HBoV, MP, and AdV during four months in 2020

HPIV increased significantly in November 2020, while HMPV increased significantly in December 2020 (Fig. 3).

\section{Discussion}

In this study, we retrospectively evaluated the overall prevalence of the most frequent respiratory pathogens among hospitalized children with ARIs before and during COVID-19 epidemic. The total positive rates of pathogens were $80.5 \%$ in 2019 and $70 \%$ in 2020 , similar to those reported in other studies (from 62.4 to 85.2\%) [6-8]. More specimens were tested in 2020 than in 2019, but the overall pathogens positive rate was significantly lower.

The detection rates of InfA, MP, HRV, and AdV decreased significantly, which led to a reduced use of oseltamivir for chemoprophylaxis and empirical use of macrolides, albeit in the epidemic season.

Droplet and contract transmission are believed to be the major transmission route of COVID-19 [9, 10]; influenza has the similar route of transmission like COVID-19. Thus, many studies have shown that nonpharmaceutical interventions associated with reduced transmission of COVID-19 have also likely substantially reduced influenza [11, 12]. Indeed, the 2019-2020 influenza season was marked by decreased influenza transmission during the COVID-19 pandemic [13]. Shenzhen is located in southern China; it has a typical subtropical monsoon climate, where influenza is mostly detected in autumn and winter [14]. Despite the school year, resumed work, and the seasonal prevalence, the influenza detection rate remained low in 2020. The potential impact of the COVID-19 pandemic on influenza is not fully known, but the reason for the observed decrease may be multifactorial. First, the COVID-19 pandemic has altered health seeking behaviors and has increased attention to nonpharmaceutical interventions that reduce the risk of transmission of influenza [13]. Other factors, such as virus competition, may have contributed as well. Namely, Lubna Pinky showed that blocking one virus infection by the presence of another can be explained simply through resource competition [15]. It has been suggested that other mechanisms, such as the immune response or interference through viral proteins, are also responsible for the growth interference between two viruses [16]. Successful containment of seasonal influenza as a result of COVID-19 control measures has provided some useful insights into controlling emerging influenza epidemics in the future.

We found that several pathogens, including RSV, HPIV, and HMPV, showed increased detection rates during the epidemic. RSV showed the most prominent increase, from 6.6 to $20.1 \%$, what was different from other studies $[17,18]$, Although there was an increased detection rate of RSV, these patients did not require specific antiviral treatment in most cases. However, isolation of RSV patients was recommended to prevent spreading of disease. RSV is detected primarily during the spring and summer in Shenzhen and is the most prevalent virus in infants [14]; in our study, the detection rate of RSV gradually decreased from September to December in both years (Fig. 2). RSV disease occurs across all ages, but it disproportionately affects children under the age of 2 years [19]; since wearing mask is difficult for children under 2 years of age, an epidemiological interference between RSV and influenza virus infections has been reported: the RSV epidemic is interrupted by an epidemic of influenza virus infection [20]. According to Takeuchi's report, the admission number of patients with RSV infection decreased during the influenza epidemic period, suggesting the presence of an epidemiological interference between RSV and influenza virus infections [21]. No cases of InfA virus were detected in 2020, which might be the reason why RSV increased in 2020 . In the 2019 and 2020 two years, we found that the detection rate of RSV decreased gradually from September to November, while the detection rate of HPIV increased gradually, and both decreased in December. It may be due to a phenomenon called viral interference where one virus blocks the growth of another virus [22]. In December 2020, the detection rate of HMPV increased significantly, while the detection rate of most pathogens decreased, and it seems that COVID-19 has no impact on the prevalence of HMPV. Mandy Jongbloed et al. has showed that HMPV and SARS-CoV-2 are probably cocirculating independently [23]. Continued monitoring of viral epidemic trends and further research are needed.

This study is limited in that it was performed in a single center in a restricted geographical area, in a short period instead of a whole year or longer period, and there was a 
preselection bias stemming from the fact that all of the patients were hospitalized. Moreover, we did not observe changes in bacteria that cause respiratory infections, which limits our observation range; We will continue our observation during the rest of the COVID-19 outbreak in a perspective, multi-centered, and larger sample sized study to provide more precise information of the changes of the pathogenic patterns in children from South China region. This could provide some useful insights for future control of emerging respiratory pathogens epidemics.

\section{Conclusions}

Nonpharmaceutical interventions used to prevent the spread of SARS-CoV-2 is also effective to reduce the transmission of influenza, especially during the early stage of a pandemic when there is a shortage of antiviral drugs and unavailability of specific vaccines. These information are important for us to plan strategies to prevent future influenza pandemic. However, there is an increased RSV rates as a result of the reduction of influenza prevalence. Thus, there is a need for close monitoring of the occurrence of RSV in the general population in the next RSV pandemic season. Further studies are needed to better understand the entire impact of COVID-19 on other pathogens.

\begin{abstract}
Abbreviations
InfA: Influenza A; InfB: Influenza B; HPIV: Human parainfluenza virus; RSV: Human respiratory syncytial virus; AdV: Adenoviruses; HMPV: Human metapneumovirus; HRV: Human rhinovirus; HBoV: Human bocavirus; HCoV: Human coronavirus; Ch: Chlamydia; MP: Mycoplasma pneumoniae; PCR: Polymerase chain reaction
\end{abstract}

\section{Acknowledgements}

Not applicable.

\section{Authors' contributions}

$\mathrm{LL}$ and $\mathrm{HW}$ have contributed equally to this work. $\mathrm{LL}$ and $\mathrm{HW}$ designed this study; AL, RW collected data; LL, HW and TZ performed the statistical analyses and outcome assessments, and wrote the paper. YZ, YB, YC and WW also contributed to the statistical analyses and the outcome assessments. All authors read and approved the final manuscript.

\section{Funding}

This work was supported by grants from the Shenzhen Fund for Guangdong Provincial High-level Clinical Key Specialties (SZGSP012) and Shenzhen Key Medical Discipline Construction Fund (SZXK032) to Wenjian Wang, which had a role in the data collection and analysis and the manuscript writing, reviewing, and editing.

\section{Availability of data and materials}

The key information and data generated and/or analyzed during this study were included in this article.

\section{Declarations}

\section{Ethics approval and consent to participate}

Ethical approval for this study was obtained from the Ethical Committee of Shenzhen Children's Hospital (Shenzhen, Guangdong Province, China) under registration number 2016013. All experiments were performed under the relevant guidelines and regulations. Guardians of all children included in this study provided written informed consent to participate.

\section{Consent for publication}

Not applicable.

\section{Competing interests}

The authors declare that they have no competing interests.

\section{Author details}

'Department of Respiratory Diseases, Shenzhen Children's Hospital, No. 7019 Yitian Road, Futian District, Shenzhen 518038, Guangdong, China. ${ }^{2}$ Department of Microbiology and Immunology, College of Basic Medicine, Guangdong Medical University, Dongguan 523808, China.

Received: 20 July 2021 Accepted: 20 September 2021

Published online: 09 October 2021

\section{References}

1. Boelle PY, Souty C, Launay T, Guerrisi C, Turbelin C, Behillil S, et al. (2020) Excess cases of influenza-like illnesses synchronous with coronavirus disease (COVID-19) epidemic, France. Euro Surveill. 2020;25(14):2000326.

2. Sakamoto $H$, Ishikane M, Ueda P. Seasonal influenza activity during the SARS-CoV-2 outbreak in Japan. JAMA. 2020;323(19):1969-71.

3. Soo RJJ, Chiew CJ, Ma S, Pung R, Lee V. Decreased influenza incidence under COVID-19 control measures, Singapore. Emerg Infect Dis. 2020;26(8):1933-5.

4. Murillo-Zamora E, Guzman-Esquivel J, Sanchez-Pina RA, Cedeno-Laurent G, Delgado-Enciso I, Mendoza-Cano O. Physical distancing reduced the incidence of influenza and supports a favorable impact on SARS-CoV-2 spread in Mexico. J Infect Dev Ctries. 2020;14(9):953-6.

5. Cheng W, Yu Z, Liu S, Sun W, Ling F, Pan J, et al. Successful interruption of seasonal influenza transmission under the COVID-19 rapid response in Zhejiang Province, China. Public Health. 2020;189:123-5.

6. Cantais A, Mory O, Pillet S, Verhoeven PO, Bonneau J, Patural H, et al. Epidemiology and microbiological investigations of community-acquired pneumonia in children admitted at the emergency department of a university hospital. J Clin Virol. 2014;60(4):402-7.

7. Akturk H, Sutcu M, Badur S, Torun SH, Citak A, Erol OB, et al. Evaluation of epidemiological and clinical features of influenza and other respiratory viruses. Turk Pediatri Ars. 2015;50(4):217-25.

8. Zhong $\mathrm{P}$, Zhang $\mathrm{H}$, Chen $\mathrm{X}$, LV F. Clinical characteristics of the lower respiratory tract infection caused by a single infection or coinfection of the human parainfluenza virus in children. J Med Virol. 2019;91(9):1625-32.

9. Mendez-Brito A, Bcheraoui CE, Pozo-Martin F. Systematic review of empirical studies comparing the effectiveness of non-pharmaceutical interventions against COVID-19. J Infect. 2021;S0163-4453(21):00316-9.

10. Leung NHL. Transmissibility and transmission of respiratory viruses. Nat Rev Microbiol. 2021;19(8):528-45.

11. Cowling BJ, Ali ST, Ng TWY, Tsang TK, Li JCM, Fong MW, et al. Impact assessment of non-pharmaceutical interventions against coronavirus disease 2019 and influenza in Hong Kong: an observational study. Lancet Public Health. 2020;5(5):e279-88.

12. Chiu NC, Chi H, Tai YL, Peng CC, Tseng CY, Chen CC, et al. Impact of wearing masks, hand hygiene, and social distancing on influenza, enterovirus, and all-cause pneumonia during the coronavirus pandemic: retrospective national epidemiological surveillance study. J Med Internet Res. 2020;22(8):e21257.

13. Maurice ADS, Martin-Blais R, Halasa N. Preparing for the 2020-2021 influenza season. Pediatr Transplant. 2021;25(5):e14025.

14. Wang H, Zheng Y, Deng J, Wang W, Liu P, Yang F, et al. Prevalence of respiratory viruses among children hospitalized from respiratory infections in Shenzhen. China Virol J. 2016;13:39.

15. Pinky $L$, Dobrovolny HM. Coinfections of the respiratory tract: viral competition for resources. PLoS ONE. 2016;11(5):e0155589.

16. Dobrescu I, Levast B, Lai K, Delgado-Ortega M, Walker S, Banman S, et al. In vitro and ex vivo analyses of co-infections with swine influenza and 
porcine reproductive and respiratory syndrome viruses. Vet Microbiol. 2014;169(1-2):18-32.

17. Nolen LD, Seeman S, Bruden D, Klejka J, Desnoyers C, Tiesinga J, et al. Impact of social distancing and travel restrictions on nonCOVID-19 respiratory hospital admissions in young children in rural Alaska. Clin Infect Dis. 2021;72(12):2196-8.

18. Varela FH, Scotta MC, Polese-Bonatto M, Sartor ITS, Ferreira CF, Fernandes IR, et al. Absence of detection of RSV and influenza during the COVID-19 pandemic in a Brazilian cohort: likely role of lower transmission in the community. J Glob Health. 2021;11:05007.

19. Hirve S, Crawford N, Palekar R, Zhang W. Clinical characteristics, predictors, and performance of case definition-Interim results from the WHO global respiratory syncytial virus surveillance pilot. Influenza Other Respir Viruses. 2020;14(6):647-57.

20. Nozomi N, Hisahide N, Jin LM, Kanjiro U. The clinical features of respiratory syncytial virus: lower respiratory tract infection after upper respiratory tract infection due to influenza virus. Pediatr Int. 2005;47(4):412-6.
21. Takeuchi Y. Epidemiological and clinical features of influenza and respiratory syncytial virus infections among children in Japan. Acta Paediatr Jpn. 1988;30(3):231-9.

22. Latorre-Margalef N, Brown JD, Fojtik A, Poulson RL, Carter D, Franca M, et al. Competition between influenza A virus subtypes through heterosubtypic immunity modulates re-infection and antibody dynamics in the mallard duck. PLoS Pathog. 2017;13(6):e1006419.

23. Jongbloed M, Leijte WT, Linssen CFM, van den Hoogen BG, van Gorp ECM, de Kruif MD. Clinical impact of human metapneumovirus infections before and during the COVID-19 pandemic. Infect Dis (Lond). 2021;53(7):488-97.

\section{Publisher's Note}

Springer Nature remains neutral with regard to jurisdictional claims in published maps and institutional affiliations.
Ready to submit your research? Choose BMC and benefit from:

- fast, convenient online submission

- thorough peer review by experienced researchers in your field

- rapid publication on acceptance

- support for research data, including large and complex data types

- gold Open Access which fosters wider collaboration and increased citations

- maximum visibility for your research: over $100 \mathrm{M}$ website views per year

At BMC, research is always in progress.

Learn more biomedcentral.com/submissions 